\title{
De la Literatura a la Historia: Cuando la locura se convierte en desviación social ${ }^{*}$
}

\author{
From Literature to History: When madness becomes social deviation
}

\begin{abstract}
Anahi Sy
Universidad Nacional de Lanús, Instituto de Salud Colectiva, Consejo Nacional de Investigaciones Científicas y Técnicas (CONICET), Buenos Aires, Argentina. Correo electrónico: anahisy@gmail.com
\end{abstract}

En este artículo se parte del análisis de dos textos literarios situados entre el último tercio del siglo XIX y la primera mitad del siglo XX, para analizar la forma en que aparecen representadas la salud y la enfermedad mental, la profesión médica, los enfermos y la relación médico-paciente, estableciendo vinculaciones con el conocimiento científico de la época. De este modo, destacamos el potencial de la ficción para representar aspectos socio-históricos y culturales, favoreciendo la lectura de una parte de la historia de la psiquiatría. Se trata de un análisis donde el "cruce" de saberes provenientes de disciplinas como la historia, la medicina, la antropología y la literatura, se puede convertir en una herramienta que permita dar cuenta de la forma en que se vinculan las épocas y sus enfermedades.

Palabras clave: salud mental, historia de la psiquiatría, antropología, literatura

This article analyzes two literary texts, located between the last third of the nineteenth century and the first half of the twentieth century, to examine how mental health and illness are depicted; the medical profession, the sick and the doctor-patient relationship; establishing links with the scientific knowledge of the time. Thus, we highlight the potential of fiction to reflect sociohistorical and cultural aspects, encouraging reading a part of the history of psychiatry. This is an analysis where the "crossover" of knowledge from disciplines such as history, medicine, anthropology and literature, becomes a tool to account for the way different epoques and their diseases are linked.

Key words: mental health, history of psychiatry, anthropology, literature

\footnotetext{
Agradezco al Fondo Nacional de las Artes que inicialmente financió este proyecto y al CONICET que actualmente financia mi trabajo de investigación. Agradezco también a Hugo Spinelli, Director del Instituto de Salud Colectiva de la Universidad Nacional de Lanús (UNLa), por la lectura de este artículo.
} 
Diferentes estudiosos de la literatura, de la medicina y su historia (Foucault 1987, 2002; Laplantine 1999; Sontag 2005; Bongers y Olbrich 2006) señalan el valor de la literatura como fuente de testimonios para pensar la enfermedad, la salud y la medicina en una época dada para analizar representaciones sociales de la enfermedad, la pluralidad de sistemas médicos, los enfermos y la relación médico-paciente, las profesiones y ocupaciones médicas, las instituciones sanitarias y su organización. La literatura, en la medida que busca contar historias, plasmar ideas, transmitir una época, recrear sensaciones, situaciones y escenarios verosímiles, tiene la capacidad de representar el modo en que son vividos, experimentados y pensados una época, un objeto-tema y/o un problema particular.

El antropólogo François Laplantine (1999), en su libro Antropología de la enfermedad, dedica varios capítulos de su obra al análisis de cuatrocientas ficciones (en su mayoría novelas), que van desde fines de 1930 a 1983 -retomando textos clásicos como La Metamorfosis (Kafka 1938), La Náusea (Sartre 1938), Doctor Faustus (Mann 1950), La montaña mágica (Mann 1960) y En busca del tiempo perdido (Proust 19701980), entre otras- para analizar la forma en que aparece representada la enfermedad en una época, la experiencia de enfermar y la cura. En su análisis establece que la literatura adopta diferentes formas de encarar la observación de "los otros" (enfermos y médicos), constituyéndose en una auténtica fuente de conocimiento científico, que resulta irremplazable. Así, el punto de vista del observador-sobre todo de un observador que sufre un síntoma o intenta curarlo- y su facultad de expresarlo mediante palabras, constituyen una rica fuente de conocimiento para una antropología de la enfermedad y la historiografía del conocimiento y las prácticas médicas. Los textos literarios, en este sentido, se constituirían en una fuente de hipótesis acerca de la realidad.

La enfermedad y la salud, analizadas desde diversas formaciones discursivas y disciplinares, generan conocimientos diferentes, incluso producen diferentes objetos (Bongers y Olbrich 2006). La exploración de tales divergencias denuncia la inestabilidad de un saber que se pretende totalizador, como lo es el conocimiento biomédico y la miopía en que nos sumerge un marco de conocimientos particulares. Cada registro produce definiciones que imprimen las "culturas profesionales", si bien siempre se trata de un saber que es a la vez histórico y cambiante a lo largo del tiempo. En este sentido, un análisis que busque trascender las barreras disciplinares hará posible al investigador visualizar su normatividad y el cuerpo de certezas sobre las que se sustenta, y de las que extraen su legitimidad social.

En este trabajo buscamos dar cuenta, a partir del análisis de las novelas Las Nubes de Juan José Saer (2006) y Nadie me verá llorar de Cristina Rivera Garza (1999), de un panorama que permite la lectura de una parte de la historia de la Psiquiatría (en consonancia con la historia de una época que la hace posible). De su comparación se desprende la co-existencia, a lo largo de la historia, de dos corrientes bien diferentes en torno al modo en que la enfermedad mental es concebida: como "enfermedad del cuerpo" (desde la perspectiva biomédica), o como "enfermedad del alma" (desde una perspectiva psico-social). Mientras la novela de Saer-situada hacia 1800- busca claramente dar cuenta de esta última posición, que luego adquirirá el nombre de antipsiquiatría, la novela de Rivera Garza busca dar cuenta de la ciencia positivista que aún prevalece hacia 1920 en el contexto institucional. 
En este sentido, es posible visualizar que los diagnósticos de locura y de enfermedad mental son productos históricos y culturales, y no únicamente biológicos. Se trata de un análisis donde el "cruce" de conocimientos que produce cada disciplina se convierte en una herramienta que nos permite acceder a la experiencia humana de enfermar y curar, históricamente situada, para hallar un espacio desde donde volver a pensarla y delinearla de otra manera.

\section{Metodología. Una mirada antropológica de la literatura como fuente de HIPÓTESIS EN TORNO A LA REALIDAD}

Este trabajo forma parte de una investigación ${ }^{1}$ que busca analizar la forma en que aparecen representadas la salud y la enfermedad mental en la literatura latinoamericana editada desde 1983 a 2008. Para profundizar en este análisis seleccionamos dos textos, por tener en común su representación histórica del problema y por la riqueza semántica que ofrece la presentación de sus personajes, situaciones y problemas que se plantean en relación al tema. En este sentido, a través de este trabajo nos proponemos dar cuenta de la medicina de una época (segundo tercio de S.XIX y primer mitad del S.XX), a través del análisis de dos textos de ficción donde aparece claramente explicitada la producción de sentidos en torno a la enfermedad mental, la profesión y la ocupación médica de la época, y la relación médico-paciente.

La estrategia analítica que nos planteamos desarrollar escapa a la crítica del análisis literario o a aquella aproximación que pudiéramos adoptar desde una perspectiva psicológica o histórica, en sentido estricto. Nuestro interés en los textos literarios se orienta a visualizar en la literatura los significados y las representaciones sociales que se promueven en torno a los procesos de salud-enfermedad, su relación con la persona que padece un problema de salud, y con el contexto histórico-social y cultural más amplio en el que adquiere pleno sentido. Para ello resulta necesario indagar en los modos en que se presenta y expresa la experiencia de enfermar, la búsqueda de un tratamiento al malestar y la cura, además del modo en que se presenta a las instituciones médicas el saber médico (en un sentido amplio), y la relación médico-paciente.

De este modo, el microanálisis que ha caracterizado a la antropología, y particularmente a la etnografía en su pretensión holística e integradora, se propone como una aproximación adecuada al análisis de estas obras literarias, haciendo posible articular diferentes niveles. Identificamos en nuestro microanálisis de los textos aquellos "signos" que dan cuenta de procesos sociales, históricos y culturales, los cuales modelan las relaciones entre los individuos y las de éstos con su entorno. Así, es posible visualizar en la literatura los aspectos que hacen posible la representación del saber, de las prácticas médicas y del sufrimiento humano en un momento histórico particular, constituyéndose en una fuente de hipótesis acerca de la realidad.

\section{FiCCIONES DE LA REALIDAD}

"cualquier semejanza con la realidad es culpa de esta última"

(Volpi Escalante 2003: 10)

Desarrollada con una beca otorgada por el Fondo Nacional de las Artes (año 2009). 
El viaje, en la literatura, siempre ha servido de alegoría para hablar sobre otros temas, "por alguna razón, desde antiguo fue proveedor de metáforas para definir la vida, el aprendizaje, las búsquedas de saberes críticos y no dogmáticos, la construcción de la subjetividad" (Ford 1994: 114). En los textos que nos proponemos analizar: Las nubes (1997) del escritor argentino Juan José Saer y Nadie me verá llorar (1997) de la escritora mexicana Cristina Rivera Garza, los personajes realizan un recorrido que nos invita a pensar en torno a la locura como un viaje, un trayecto o una búsqueda de nuevos significados y significantes para definir y nombrar "la realidad". En este sentido, aparecen plasmadas ideas en torno a la salud-enfermedad mental que encarnan en cada novela personajes bien diferenciados, si bien convergen en el hecho de que deben transformar la realidad en signo para probar que las figuras que muestran los libros dicen la verdad -como lo señala Foucault (2002) para Don Quijote-.

\subsection{La incertidumbre de lo real}

"el engaño es superfluo porque la locura, por el solo hecho de existir, vuelve a la verdad problemática’"

(Saer 2006: 28).

Las nubes nos permite reflexionar especialmente en torno a la distinción entre "normal-anormal", que remite de inmediato a la dicotomía entre razón y "locura", así como a la arbitrariedad / limitación de las categorías con que contamos para aprehender la realidad. La novela de Saer describe el peregrinaje del doctor Real, discípulo del psiquiatra Weiss, que en 1802 funda la primera clínica psiquiátrica en todo el territorio americano: la Casa de Salud. Estos personajes, recién llegados de Francia, se construyen en torno al fervor que había provocado la liberación de sus cadenas a los locos, hecho que gran parte de la historia ha atribuido a Philippe Pinel quien, en 1793, decidió reformar la manera de tratar a quienes se hallaban internados, pidiendo autorización para suprimir el uso de cadenas en el hospital Salpetrierè2. Los doctores Weiss y Real, formados en un contexto donde se buscaba la humanización del tratamiento médico, colocan la explicación de los padecimientos que buscan atender en el alma. El mismo Real se presenta: "soy el doctor Real, especialista de las enfermedades que desquician no el cuerpo, sino el alma” (Saer 2006: 20).

Con el establecimiento de la clínica, el doctor Real queda a cargo de llevar a cinco locos a la Casa de Weiss, desde Santa Fe hasta Buenos Aires. Se organiza una caravana de treinta y seis personas que, demasiado lenta y demasiado larga, atraviesa la pampa y sus amenazas, luchando contra las inclemencias climáticas, bordeando inundaciones, salvándose azarosamente del fuego en la llanura, y sobreviviendo al encuentro con el indígena: la tribu del cacique Josesito, Mocoví, que se había alzado tiempo atrás atacando los puestos, las poblaciones y las caravanas, y sobre el cual versaban las historias más temibles de las pampas. Ese paisaje impone al doctor Real una sensación de extrañamiento que lo induce a la reflexión sobre las categorías

Tales hechos, descritos por Foucault en Historia de la locura, aparecen cuestionados por la historiadora Gladis Swain, señalando que no fue Pinel el autor de ese acto, sino que el papel central y la progresiva liberación de las cadenas fue del enfermero Pussin. Demostrando que "la psiquiatría no había nacido de un acto de liberación de los locos (necesariamente mítico), sino de la atribución al alienista de los poderes que antes ejercían los enfermeros" (Roudinesco et al. 1996: 22). 
de sentido convencionales utilizadas para aprehender la realidad. Entonces, surge la pregunta: ¿es posible una representación de la realidad?

El doctor Real, al narrar la experiencia del viaje al Dr. Weiss, señala:

Una idea absurda se me ocurrió: me dije que, desterrado de mi mundo familiar, y en medio de ese silencio desmesurado, el único modo de evitar el terror consistía en desaparecer yo mismo y que, si me concentraba lo suficiente, mi propio ser se borraría arrastrando consigo a la inexistencia ese mundo en el que empezaba a entreverse la pesadilla. Pero mi conciencia, rebelde, persistía, susurrándome: si este lugar extraño no le hace perder a un hombre la razón, o no es un hombre, o ya está loco, porque es la razón lo que engendra la locura (p. 161).

A esta reflexión de Real, el Doctor Weiss responde: "Entre los locos, los caballos y usted, es difícil saber cuáles son los verdaderos locos. Falta el punto de vista adecuado. En lo relativo al mundo en el que se está, si es extraño o familiar, el mismo problema de punto de vista se presenta. Por otra parte, es cierto que locura y razón son indisociables" (p. 162).

Así, aparece la idea de un lenguaje propio del "loco", inaccesible a nuestra capacidad de comprensión que, al igual que el paisaje, los hechos y las peripecias del viaje, se torna ficticio porque es un lenguaje para el cual "ellos solos poseen la significación. De modo que cuando queremos conocer sus representaciones, descubrimos que son tan inaccesibles para nosotros como las de un animal privado de lenguaje" (p. 162).

Aparece entonces la imagen -inaccesible, carente de significado- de "el otro" y "lo otro", denunciando la arbitrariedad de las categorías, es decir, de las herramientas con las que contamos para la comprensión cotidiana. Es en la razón donde la locura encuentra su posibilidad de ser. Así, los locos se convierten en la "excusa" que le permite a Saer dar cuenta, de modo tangible y evidente, de aquello que, expresado sólo en el paisaje o apelando a otros personajes, resultaría vago.

¿Quiénes eran estos locos a quienes Real venía a trasladar para su cura?:

- Prudencio Parra, quien oscila entre su dedicación a los estudios filosóficos y la predicación de sus escritos, sufriendo frecuentes accesos de melancolía. Así lo encuentra Real, inmóvil en su habitación, con el puño izquierdo cerrado.

- Sor Teresita, quien ha caído en un éxtasis místico-sexual y proclama que Jesús fue crucificado porque "la tenía así de grande". Según la monjita, Cristo le había ordenado consumar la unión carnal con el hombre, y la unión divina con el Espíritu Santo, para alcanzar de esa manera la perfecta unión con Dios; eso la obsesionaba, acosando a cualquier hombre que aparecía ante sus ojos.

- Troncoso y su programa político destinado a cambiar los fundamentos de la sociedad y del universo: "Troncoso sigue siendo el ejemplo mismo de autonomía de la locura que, no por ser servidumbre evidente de causas que todavía nos son desconocidas, son menos corrosivas de las certezas bastante injustificadas de la buena salud" (p. 127).

- Los hermanos Verde, con su continuo asedio pre-verbal al que sometían a sus interlocutores; el mayor, Juan, sólo habla repitiendo la expresión "mañana, tarde y noche", cambiando únicamente la entonación para sugerir con ella cosas tan distintas como el saludo, la cortesía, el asombro, la alegría, el enojo, la controversia, la concentración o el interés. Su hermano, Verdecito, hace repetir varias veces las 
frases que se le dirigen -como si no escuchara bien-, aunque lo más exasperante es su costumbre de producir continuamente toda clase de ruidos con la boca: gritos, gruñidos, estornudos, hipos, toses, tartamudeos, ventosidades bucales y hasta aullidos y alaridos, en momentos de gran excitación.

Así, el médico señala que sus locos pueden dividirse en dos clases: quienes se hallan encerrados en su "celda estrecha", prescindiendo de lo exterior (Parra y los Verde), y quienes militaban su locura, buscando convencer al mundo de sus delirios (Troncoso y Sor Teresita).

En este espacio donde tantas cosas parecen carecer de referente lingüístico, palabra o concepto que permita darles algún sentido, los doctores Weiss y Real $-\mathrm{y}$ su Casa de Salud- vienen a inaugurar un espacio para aquello que hasta el momento carecía tanto de nombre como de lugar:

Las familias ricas no sabían qué hacer con sus locos (...) por proteger su propia reputación, no se resignaban a dejarlos herrar por las calles como lo hacen los pobres con los suyos" (...). Desde antes de su inauguración el número de familias postulantes fue asombrosamente elevado (...), mostró la gran necesidad que existía en América de un lugar donde se trataran, con los últimos adelantos de la ciencia, la frenitis, la manía, la melancolía y otras dolencias del alma más o menos conocidas. A decir verdad, hasta que llegamos el doctor Weiss y yo a tratar de curarlas, esas enfermedades no parecían existir en las clases superiores de América, de lo que corresponde inferir el silencio que reinaba en todo el continente sobre el tema (pp. 23-24).

Los doctores vienen a ponerle un nombre a lo desconocido, a lo que se esconde, lo que no se nombra, a la invisibilidad que hasta ese momento tenía aquello que ahora adquiere el status de enfermedad. Como lo piensa el doctor Real: para la ciencia que ha hecho del "loco" su objeto, éste representa un enigma, pero para sus familias, un problema.

No obstante, al mismo tiempo, estos "objetos" que la ciencia nombra, clasifica y ordena, dándoles un lugar en el mundo de lo real, muestran lo acotado y arbitrario de nuestros pensamientos. En este sentido, todo podría reducirse, como dice Weiss, a un "problema de punto de vista (...) únicamente la locura se atreve a representarse aquellos límites del pensamiento que a menudo la cordura, para seguir justamente siendo cordura, prefiere ignorar" (p. 81). La locura es algo temible, algo de lo que se busca escapar, que molesta, irrumpe, perturba:

Hay mucha gente que piensa que la locura es contagiosa: si lo es, lo es menos porque, en presencia de un loco, los que lo rodean adquieren sus mismos síntomas, que porque la locura es tan corrosiva que, alterando a los que deben convivir con ella, hace surgir en ellos síntomas propios que en tiempos normales seguirían dormidos, y como esa alteración se produce por vía nerviosa, sin que la razón o la voluntad de los que la sufren intervenga para nada (p. 171).

¿Cómo saber que la aventura de Real no es la obra de un "loco militante" tanto como esos que él describe? El nombre "Real" resulta sugerente, la pregunta ¿cómo aprehender lo "Real"? puede ser objeto de una doble lectura o interpretación. 
A propósito de las dificultades que encuentra para reconocer lo que él llama las enfermedades del alma, dice:

Esa incapacidad de reconocer la locura, no es de ningún modo algo poco corriente, y hasta me atrevería a afirmar que constituye más bien la norma, y que no se trata de un fenómeno que concierne a individuos aislados, sino a naciones enteras que, como la historia lo ha mostrado ya repetidas veces (...), se dejaron conducir al abismo por la extraña capacidad de persuasión que posee la lógica en apariencia sin defectos del delirio, aunque toda ella sea en sí defección (p. 103).

En este sentido, busca quitarle el carácter exótico a los hechos que describe, estableciendo una analogía con procesos macrosociales que funcionan de manera similar.

Ya desde el inicio de la novela sabemos la suerte que corrió la Casa de Salud con la guerra por la independencia. El doctor Real nos dice: "los revolucionarios nos acusaban de realistas y los realistas de revolucionarios" (p. 40). Acusados de “espías" por haber obtenido autorización de la corona para su instalación, lo cierto es que ellos terminan huyendo antes de que los maten, la casa queda abandonada y los "enfermos" se dispersan.

\subsection{El médico como "empresario moral"}

"El manicomio tiene veinticinco edificios diseminados en 141.662 metros cuadrados.

Dentro, protegidos por altos muros y rejas de hierro, los locos y los castaños proyectan sus sombras sobre lugares apartados del tiempo"

(Rivera Garza 1999: 43)

La novela Nadie me verá llorar de Cristina Rivera Garza transcurre en México, entre 1900 y 1920, donde, desde fines del siglo XIX y, más aún en las primeras décadas del siglo XX bajo el gobierno de Porfirio Díaz, se propuso ingresar en la modernidad. En dicho proceso, la lucha de clases se expresó, entre otras formas, en el dominio del cuerpo del otro. Los "científicos" formaban parte de los estratos sociales dominantes. El discurso ideológico sobre el pueblo como beneficiario del cambio fue la cara aceptable de la modernidad, pero esa modernidad implicaba, paradójicamente, también "limpiar" las calles de prostitutas y enfermos para que esos espacios fuesen ocupados por la sociedad "sana". Para ello se construyeron instituciones modelo, entre ellas, el manicomio de La Castañeda, donde se sitúa la novela.

La novela desarrolla la historia de Matilda Burgos, a partir de su encierro en el hospital de Salud Mental La Castañeda y su encuentro con el fotógrafo Joaquín Buitrago, dedicado a tomar fotografías en ese lugar. Bajo el amparo del reglamentarismo y de las ideas higienistas, se establece hacia 1867 un control sanitario sobre las prostitutas, por medio de exámenes médicos obligatorios con los que se pretendió garantizar la salubridad pública. La fotografía fue utilizada en el control de "las mujeres de la calle" como una forma de identikit sanitario y policial, del mismo modo que servía para llevar el control en los hospitales.

La figura del fotógrafo, en la novela, aparece con una personalidad solitaria, adicto a la morfina, en apariencia perteneciente a una familia de la burguesía de la que 
él ha decidido renegar. Se obsesiona con la figura de Matilda, cree haberla conocido años atrás en el burdel La Modernidad. Buscando develar su identidad, entabla una relación con el doctor Eduardo Oligochea, psiquiatra del hospital. Ambos buscan "leer" a Matilda desde perspectivas muy diferentes. El fotógrafo, humanamente, atraviesa la novela con la pregunta que Joaquín le hace a Matilda: ¿cómo se convierte uno en una loca?, ante la cual Matilda responde: ¿cómo se convierte uno en fotógrafo de locos? Mientras tanto, el médico Oligochea encarna el discurso racionalizador, cientificista, que busca un orden claro de las cosas:

'toxicomanía', 'histeria', 'esquizofrenia'. Ésos son los nuevos nombres para quienes han perdido el deseo por la vida. Una de las debilidades del doctor Oligochea es el orden. Tanto en su escritorio como en su cabeza, los objetos y las palabras se mueven con ritmos metódicos, siguiendo patrones rigurosos pero nimbados de armonía (pp. 102-103).

Por el contrario, Joaquín actúa buscando subvertir, cuestionar ese orden de cosas establecido, donde a cada palabra y a cada conducta le corresponde una categoría que describe el carácter patológico de los internos. Un día en que se acerca al médico buscando conocer algo más sobre Matilda, Oligochea le dice "Matilda sigue contando las historias de siempre", y el fotógrafo se anima a enfrentarlo abiertamente: "tal vez son las únicas historias que tu sabes oír" (p. 112). La reacción del psiquiatra en ese momento resulta contundente respecto a su diagnóstico: “¿De qué me está hablando, Buitrago? ¿Es que no leyó su expediente? Vea. Chancros sifilíticos. Bubas. Placas en el labio inferior. Consumo de éter. ¿Y no ha notado su logorrea al hablar? Ésa es su historia. La única historia. La historia real y no su romanticismo trasnochado, Joaquín" (p. 112).

En este contexto, vemos cómo el médico es capaz de patologizar cualquier parecer que se aparte de su saber: "No es que yo no sepa oír, lo que pasa es que usted está oyendo voces que no existen". Joaquín agrega "La prueba de Wasserman salió negativa" (p. 112). Sin embargo, el juicio del médico parece definitivo: "Cierto, pero todos los síntomas de Matilda indican demencia. La verborrea, el sobresalto, el exceso de movilidad, la anomalía de su sentido moral. No me vaya a decir que cree en la veracidad de sus historias" (p. 112).

De este enfrentamiento Joaquín no sale ileso, y la relación que mantenía con Oligochea se modifica automáticamente. El médico en seguida lo coloca en el lugar de enfermo "toxicómano", dada su adicción a la morfina, mientras, ante la mirada inquisitiva del médico y la amorosa de Joaquín, "Matilda añora más que nunca vivir en un universo sin ojos, un lugar donde lo único importante sean las historias relatadas de noche. El silencio. Las miradas masculinas la han perseguido toda la vida" (p. 125).

"Nadie me verá llorar" se dice a sí misma Matilda Burgos al llegar a la ciudad de México, proveniente de una familia campesina de raigambre indígena. Cuando su padre fallece, su madre decide enviarla a México, al cuidado de su tío, Marcos Burgos, que ella no conocía y del cual su madre apenas sabía que se hallaba en una posición económica favorable.

Marcos Burgos, psiquiatra de profesión, aparece como seguidor de la teoría del médico y criminólogo positivista Césare Lombroso (1835-1909), según la cual existía toda una serie de rasgos físicos (que tenían una correlación genética) a partir de los cuales era posible identificar la personalidad de los "criminales", "locos" y "alienados". 
En este sentido Burgos sostiene que "su práctica médica entre los pobres de la ciudad le confirmó sus teorías: todas las patologías estaban directamente relacionadas con la falta de higiene, tanto física como mental del populacho" (p. 126). En este sentido, busca mostrar con Matilda la posibilidad de revertir la "tendencia genética" a la "mala" vida que ella había heredado de su padre alcohólico y de su madre enferma de Tifus; la criaría de acuerdo a la moral y los valores burgueses de la época.

Finalmente, Matilda termina escapando del cuidado de su tío y entra en contacto con la revolución; las necesidades y la realidad del momento la conducen por diferentes caminos que dan clara cuenta del control sobre los cuerpos que mina cada espacio de la sociedad, aún en los inicios del siglo XX, desde los prostíbulos (con las leyes de salubridad) hasta la institución manicomial. Resulta interesante que ella no es presentada como víctima de esa situación, sino como una mujer que por distintas circunstancias ejerce la prostitución e intenta construir su propio destino a partir de ello.

De tal forma, vemos el contraste entre un afuera, que le exige la elaboración constante de una historia personal ante la mirada del otro, y el encierro, sinónimo de locura, que no le reclama siquiera palabras, donde es posible el silencio, la negación de un pasado, una historia; en fin, la existencia invisible, autista. La búsqueda de Matilda es la búsqueda por escapar de la mirada de los otros, convertirse en ausencia, algo que sólo logra con su muerte: "Con deseo o con exhaustividad, animadas por la lujuria o por el afán científico, los ojos de los hombres han visto, medido y evaluado su cuerpo primero, y después su mente, hasta el hartazgo. En la luz húmeda de julio, lo único que desea es volverse invisible" (p. 236).

La locura se revela en Matilda como el modo en que ella puede escapar, denunciar y subvertir normas sociales que le resultan opresivas. Su encierro y aislamiento en el hospital coinciden, en parte, con su deseo de no ser mirada, de no ser buscada. $\mathrm{Su}$ locura le permite mantenerse en un silencio profundo. Un día Matilda le dice a Joaquín "ya no tengo ganas de hablar, Joaquín”, y Joaquín le responde: "así es como uno se vuelve loco, ¿no es cierto?” aunque Matilda replica: “cada quien encuentra su modo" (p. 239).

Sólo hacia el final de la novela aparecen los pensamientos de Matilda, plasmados en cartas escritas durante su encierro en el hospital. Tales cartas resultan herméticas, no adhieren al orden establecido convencionalmente en la estructura del relato, como en el texto de Saer -aunque de forma más burda-, puede observarse la idea de un lenguaje inaccesible a la "normalidad".

Observamos así que esta búsqueda de Matilda es también la de Joaquín, ambos situados en los márgenes de lo moralmente correcto. Joaquín reflexiona sobre su oficio de fotógrafo: "de eso se trataba todo: ver sin ser visto" (p. 187), su deseo de volverse invisible a la mirada y los juicios ajenos; y eso sólo lo provee la morfina, y luego Matilda. El espacio manicomial, situado en los márgenes de la sociedad, está plagado de personas sin historia que les ofrece esa posibilidad.

Las cartas de Matilda no aparecen acompañadas de ninguna interpretación externa. En última instancia, lo que nos está diciendo es que sólo ella tiene acceso a sus pensamientos y percepciones individuales, esto es, que cualquier intento por representarlos, sea a través de la autoridad médica, sea a través de la novela en sí misma, está condenado al fracaso.

En suma, la novela de Rivera Garza revela el confinamiento, el aislamiento y la soledad que sufren quienes se hallan internados en instituciones de salud mental. 
Cómo la autoridad médica, por encima de cualquier hecho, contribuye a rotular y clasificar para terminar aislando al individuo de su entorno, quitándole su estatus de sujeto para convertirlo en enfermo (paciente). Y esto ocurre de una manera tan cruda que el mismo paciente termina buscando deliberadamente esa vida.

\section{CO-EXISTENCIAS Y CONTRASTES}

Las vivencias de los personajes que encarnan la historia de la novela de Rivera Garza permiten visualizar la crudeza que puede esconderse tras la pretendida objetividad y "defensa de la verdad" de la ciencia positivista, sus teorías y la aplicación de las mismas. En este sentido, establece un contraste con la novela de Saer y, de la relación entre ambas, se desprende la co-existencia, entre fines del S. XIX y principios del S. XX, de dos corrientes bien diferentes en torno al modo en que la enfermedad mental es concebida: como "enfermedad del cuerpo" (biológica), o como "enfermedad del alma" (psico-social).

Mientras la novela de Saer busca dar cuenta de esta última posición, con referencia a un hecho histórico discutido, la novela de Rivera Garza da cuenta de la ciencia positivista que prevalece en ese momento en el contexto institucional. De su comparación se derivan, a la vez, problemas en común que existen para representar "al otro", al "loco"; si bien en la primera se decanta por la incertidumbre, en la segunda se decanta por el juicio basado en la certeza que provee el saber biomédico, hegemónico en ese momento.

La visualización de la locura como "enfermedad del cuerpo", tal como aparece en la novela de Rivera Garza, permite identificar el modo en que se ha ido construyendo la noción de enfermedad, como desviación de un conjunto de normas que representa la salud o la normalidad. Nadie me verá llorar expresa claramente el rol del médico como "empresario moral". Así, la medicina resulta análoga al derecho y la religión, proponiéndose descubrir y controlar aquellas cosas que considera indeseables. La medicina higienista que se describe en la novela da cuenta de ello, en el momento histórico en que opera este pasaje del dominio de la autoridad religiosa y/o la figura jurídica al dominio de la autoridad médica.

En este contexto, puede reconocerse que es la visión de la medicina científica la que está sancionada oficialmente. La medicina empieza a verse como creando las posibilidades sociales para representar la enfermedad e instalarla como rol social oficial, los estudios de Foucault (1987 y 2002) y Friedson (1978) resultan especialmente elocuentes de ello $^{3}$. En este escenario, la medicina se convierte preeminentemente en un instrumento de control social, la dimensión del "por qué" o de las causas de la enfermedad se proyecta precisamente sobre los valores que confieren sentido a la vida, forzándonos a examinar las causas morales y sociales de la enfermedad (Friedson 1978; Taussig 1992; Foucault 2002).

La calle, los prostíbulos y los manicomios se convierten de igual modo en espacios e instituciones de control social, bajo la legislación salubrista en el México Porfiriano y en los albores de la post-revolución. Sin embargo, la novela, al otorgarle protagonismo al personaje del paciente - esto es, a través de su palabra, pensamientos

\footnotetext{
Al respecto Foucault $(1987,2002)$ describe claramente la fuerza normativa del discurso médico-clínico y sus consecuencias para la organización de la vida social en los siglos XVIII y XIX. Mientras que Freidson desarrolla una crítica al saber médico profesional que resulta pionera en el campo de la Sociología Médica.
} 
y trayectoria de vida-, se permite interpelar el conocimiento médico de la época, para formular una crítica hacia la arbitrariedad de los diagnósticos y los tratamientos que esta ciencia realiza, que son a la vez la base misma de su existencia y sentido.

En la novela Las nubes aparece una representación de la locura "a medio camino" entre, por un lado, la imagen romántica de la enfermedad que prevaleció hacia fines del siglo XVIII y principios del XIX, donde la enfermedad convierte al hombre en una persona sensible, de capacidades y dotes especiales ${ }^{4}$. Y por otro lado, se vincula a movimientos posteriores de reforma institucional, como el de la antipsiquiatría ${ }^{5}$, que se instalan hacia 1960 cuestionando las prácticas psiquiátricas tradicionales $\mathrm{y}$, en consecuencia, las estructuras ideológicas que contribuyen a su mantenimiento desde mediados del siglo XIX. Desde esta perspectiva, la "enfermedad mental" no es un fenómeno psicológico individual o fisiológico, sino un fenómeno social producido por la misma sociedad, que cree poder dictaminar sobre la naturaleza de la enfermedad mental y de la locura.

La novela de Saer muestra que el loco puede perder la cordura, pero no completamente la razón. Dado que su racionalidad nos resulta completamente ajena a la realidad que habitamos y a las estructuras de sentido convencionales, el loco estaría poniendo en evidencia que tales estructuras no son más que un artificio, el resultado de una construcción social y cultural. En esta línea, la locura puede ser "contagiosa", invitando a quienes la observan, desde su extrañamiento, a re-pensar la realidad. De este modo, se acerca a lo planteado por Foucault cuando establece que la locura es un problema "epistemológico", un problema que sólo tiene sentido dentro de una determinada episteme. La separación de la locura respecto de la razón no quiere decir que la locura sea completamente independiente de ésta, sino que es una forma relativa a la razón, sirve de espejo o contra espejo a aquello que la relega. En este sentido, la línea de separación entre locura y razón persistirá mientras continúe la episteme dentro de la cual el discurso del "loco" es un discurso rigurosamente excluido, como ocurre desde una perspectiva biomédica (Foucault 1987, 2002).

Por último, resulta especialmente claro este último planteamiento en la novela de Rivera Garza, donde aparecen cuestiones claramente vinculadas a una episteme de las

\footnotetext{
Como lo describe Sontag para el caso de la tuberculosis, ésta es considerada síntoma de delicadeza y sensibilidad, sobresaliendo la idea "del paciente en tanto que criatura turbulenta, descuidada, de extremadas pasiones, demasiado sensible para soportar el horror del mundo cotidiano y vulgar" (2005: 40-41). Este imaginario se plasma claramente en La montaña mágica: "la enfermedad es perfectamente humana, pues ser hombre es estar enfermo. En efecto, el hombre es esencialmente un enfermo, y el hecho de que esté enfermo es precisamente lo que hace de él un hombre (...) es pues del espíritu de la enfermedad de lo que depende la dignidad del hombre y su nobleza. En una palabra, es tanto más hombre cuanto más enfermo está, y el genio de la enfermedad es más humano que el genio de la salud" (Mann 1949: 11).

Si bien el término antipsiquiatría fue acuñado por el terapeuta y filósofo David Cooper en su obra Psiquiatría $y$ antipsiquiatría (1967), el comienzo de este movimiento podemos situarlo en 1957 cuando el psiquiatra norteamericano T. Szasz pone en duda la realidad de la enfermedad mental en su obra Dolor y placer. En 1960, Szasz publica El mito de la enfermedad mental, considerada como fundadora de la antipsiquiatría (aunque el autor nunca se consideró antipsiquiatra). En este trabajo parte de un extenso análisis de la histeria para cuestionar toda la nosología psiquiátrica imperante, concibiendo las supuestas enfermedades mentales como modalidades de comunicación, un "protolenguaje" que, en vez de recurrir a símbolos verbales, emplea signos icónicos, como el sueño y las fantasías. Desde esta perspectiva, señala que los psiquiatras no se enfrentan con patologías verdaderas, sino con dilemas éticos, sociales y personales. Ese mismo año Ronald D. Laing, una de las figuras representativas de la antipsiquiatría, publica El yo dividido, obra con clara influencia fenomenológica existencialista, que resalta la importancia de las relaciones familiares en el inicio y la evolución de los síntomas psicóticos. Estas investigaciones se traducen en diferentes prácticas, alternativas al modelo de internación y tratamiento vigentes en la época.
} 
ciencias de la salud basadas en el método Hipotético Deductivo y las comprobaciones inductivas (experimentales), orientadas por la legitimación científico-positivista de todo conocimiento que es presentado como "la verdadera perspectiva científica frente a la salud" (Samaja 2004: 34), acorde a los criterios de las Ciencias Naturales.

\section{CONSIDERACIONES FINALES}

Si bien la literatura puede trabajar con diversos grados de conciencia en el proyecto de hallar y destacar correlaciones íntimas entre las épocas y sus patologías, entre las imágenes de la enfermedad y la época (Horisch 2006), los medios de expresión del arte resultan inseparables de la concepción de la vida y del mundo que lo anima, en cuya formación participa el conjunto de la vida. Algo similar ocurre con los espacios, en este caso la ciudad, que puede ser entendida como un "espejo" de la organización social de sus habitantes, del sistema de poder que la vertebra, y, a otra escala, aunque espejo de lo mismo, de las instituciones sociales que emergen en cada época.

Sin embargo, gran parte de los análisis sobre la salud y la enfermedad tienden a ser realizados desde marcos de referencia de disciplinas diferenciadas: salud pública, medicina, filosofía, epidemiología, historia, antropología, ecología, etc. Cada uno de esos campos se junta con otros para armar el ámbito real de lo vivido, cuestión que tiende a olvidarse: que esto ocurre/ocurrió en la vida de la gente; "las personas sufren padecimientos clasificados en categorías separadas pero los sufre simultánea e intextricablemente" (Berger 2011:40).

A través de este trabajo podemos observar que la literatura, por el carácter de verosimilitud que exige la construcción de una obra, responde al carácter integral que adquiere la experiencia humana de enfermar y curar, en este caso, dando cuenta del ser humano tanto en su dimensión biológica, como social y cultural, situado en un contexto histórico particular. Al mismo tiempo, el carácter ficcional de los personajes que construye, permite elaboraciones que llevan al límite y exacerban ciertas cuestiones que hacen especialmente visibles y evidentes situaciones que en nuestra sociedad aparecen de modo más sutil o solapado. Por ejemplo, en las novelas analizadas, el cuestionamiento a la posibilidad de considerar una "normalidad", aquella que reclama nuestra sociedad a partir del establecimiento de dicotomías tradicionales como: "normal/anormal", "sano/enfermo".

$\mathrm{Si}$, por un lado, podemos estar seguros de que los avances en el conocimiento científico-tecnológico van produciendo transformaciones en el saber en torno a la salud-enfermedad-atención (desde una perspectiva biomédica), también debemos tener presente que los cambios sociales y culturales intervienen, además, en la forma en que éstos se desarrollan y expresan. A la vez, estos cambios se traducen en la producción de padecimientos subjetivos, cuya expresión a lo largo de la historia sólo puede ser rastreada a través de sus manifestaciones culturales, de entre las cuales nosotros hemos seleccionado la literatura.

\section{OBRAS CITADAS}

Berger, John. 2011. Con la esperanza entre los dientes. Buenos Aires: Alfaguara.

Bongers, Wolfgang y Tanja Olbrich (Comps.). 2006. Literatura, cultura, enfermedad. Buenos Aires: Paidós. 
Ford, Aníbal. 1994. Navegaciones. Comunicación, cultura, crisis. Buenos Aires: Amorrortu.

Foucault, Michel. 1987. El nacimiento de la clínica. Una arqueología de la mirada médica. Buenos Aires: Siglo XXI.

2002. Historia de la locura en la época clásica. México D.F.: Fondo de Cultura Económica.

Freidson, Eliot. 1978. La profesión médica. Barcelona: Península.

Horisch, Jochen. 2006. "Las épocas y sus enfermedades. El saber patognóstico de la literatura”. En Bongers, Wolfgang y Tanja Olbrich (Comps.), Literatura, cultura, enfermedad. Buenos Aires: Paidós. 47-65.

Laplantine, François. 1999. Antropología de la enfermedad. Buenos Aires: Ediciones del Sol. Mann, Thomas. 1949. La montaña mágica. Buenos Aires: Editorial Edhasa.

Miranda, Marisa y Gustavo Vallejo (Comps.). 2005. Darwinismo social y eugenesia en el mundo latino. Buenos Aires: Siglo XXI.

Rivera Garza, Cristina. 1999. Nadie me verá llorar. México D.F.: Tusquets.

Roudinesco, Elisabeth. 1996. "Lecturas de la Histoire de la folie (1961-1986). Introducción". En Roudinesco, Elisabeth et al., Pensar la locura. Ensayos sobre Michel Foucault. Buenos Aires: Paidós. 9-32.

Saer, Juan José. 2006. Las nubes. Buenos Aires: Seix Barral.

Samaja, Juan. 2004. Epistemología de la salud. Reproducción social, subjetividad y transdisciplina. Buenos Aires: Lugar Editorial.

Sontag, Susan. 2005. La enfermedad y sus metáforas. El sida y sus metáforas. Buenos Aires: Taurus.

Taussig, Michael. 1992. "La reificación y la conciencia del paciente". En Taussig, Michael, Un gigante en convulsiones. El mundo humano como sistema nervioso en emergencia permanente. España: Gedisa. 110-143.

Volpi Escalante, Jorge Luis. 2003. El fin de la locura. Barcelona: Seix Barral. 
